\title{
METODE PSEUDOSPEKTRAL CHEBYSHEV PADA APROKSIMASI TURUNAN FUNGSI
}

\author{
ILHAM FEBRI RAMADHAN \\ Program Studi Matematika, \\ Fakultas Matematika dan Ilmu Pengetahuan Alam, Universitas Andalas, \\ Kampus UNAND Limau Manis Padang, Indonesia, \\ email : 15ilhamfebri@gmail.com
}

\begin{abstract}
Abstrak. Metode pseudospektral Chebyshev merupakan metode alternatif selain metode beda hingga untuk mengaproksimasi turunan suatu fungsi. Pada makalah ini akan dijelaskan proses konstruksi metode pseudospektral Chebyshev. Matriks diferensiasi pada metode ini diperoleh dari turunan polinomial yang menginterpolasi titik-titik diskritisasi dari fungsi yang akan dicari turunannya. Diskritisasi fungsi tersebut diperoleh dengan menggunakan titik Chebyshev. Metode pseudospektral Chebyshev ini kemudian dibandingkan dengan metode beda hingga melalui implementasi numerik terhadap suatu fungsi. Hasil perbandingan yang diperoleh menunjukkan bahwa metode pseudospektral Chebyshev menghasilkan galat yang jauh lebih kecil dibandingkan dengan metode beda hingga.

Kata Kunci: Metode beda hingga, metode pseudospektral, titik Chebyshev, matriks diferensiasi
\end{abstract}

\section{Pendahuluan}

Banyak fenomena alam dalam kehidupan sehari-hari yang bersifat dinamis atau selalu berubah, seperti mekanika kuantum, getaran dawai, gelombang laut, dan lainlain. Secara matematis, fenomena-fenomena tersebut dapat dimodelkan ke dalam persamaan diferensial.

Tidak semua persamaan diferensial dapat dihitung secara analitik, sehingga untuk menyelesaikan persamaan diferensial tersebut perlu dilakukan secara numerik.

Metode konvensional yang paling sering digunakan untuk mengaproksimasi turunan suatu fungsi adalah metode beda hingga (finite difference method). Pada metode ini domain suatu fungsi dipartisi menjadi sejumlah titik dan rumus aproksimasi untuk turunan diperoleh dari ekspansi deret Taylor pada satu atau lebih titik partisi [4]. Secara umum, metode ini relatif mudah untuk diterapkan pada semua aplikasi program komputasi. Galat yang dihasilkan dari metode ini juga dapat dibuat sesuai keinginan. Namun kelemahan dari metode ini adalah semakin kecil galat yang diinginkan, maka semakin banyak pula titik partisi yang dibutuhkan. Akibatnya, beban komputasi juga akan semakin berat.

Untuk mengatasi kelemahan yang dimiliki oleh metode beda hingga ini, dikembangkanlah suatu metode alternatif yang dinamakan metode pseudospektral. Metode ini dapat mengaproksimasi turunan suatu fungsi dimana jumlah titik partisi yang digunakan lebih sedikit, yaitu mengurangi beban komputasi, tetapi galat 
yang diperoleh jauh lebih kecil dibandingkan dengan metode beda hingga. Metode ini diinisiasi oleh Orszag dkk sejak tahun 1970an ketika menyelesaikan masalah dinamika fluida dan meteorologi [5].

Pada awalnya metode ini dikonstruksi untuk turunan fungsi periodik dengan menggunakan interpolasi deret Fourier di titik-titik partisi yang berjarak sama (lihat referensi [3] untuk melihat penurunannya lebih detail). Selanjutnya untuk turunan fungsi nonperiodik, metode ini dikonstruksi dengan menggunakan interpolasi polinomial di titik-titik partisi yang berjarak sama. Namun secara umum cara ini menimbulkan masalah dalam kekonvergenannya, karena fungsi interpolasi yang dihasilkan berosilasi di sekitar titik-titik ujung interval. Fenomena ini kemudian dikenal sebagai fenomena Runge [5]. Untuk mengatasi hal ini, dikembangkanlah suatu interpolasi polinomial dengan titik-titik partisi yang berjarak tidak sama. Interpolasi polinomial seperti ini dikenal sebagai interpolasi polinomial Chebyshev dan metode pseudospektral yang dikonstruksi dari interpolasi ini disebut metode pseudospektral Chebyshev.

Dalam makalah ini akan dibahas konstruksi metode pseudospektral Chebyshev dan perbandingannya dengan metode beda hingga dalam mengaproksimasi turunan suatu fungsi. Kajian pada makalah ini mengeksplorasi kembali pembahasan pada [5] dengan melengkapi sendiri bukti teorema tentang matriks diferensiasi pada referensi tersebut.

\section{Polinomial Chebyshev}

Definisi 2.1. [2] Polinomial Chebyshev jenis pertama $T_{N}(x)$ berderajat $N$ didefinisikan sebagai

$$
T_{N}(x)=\cos N \theta \quad \text { dengan } \quad x=\cos \theta .
$$

Definisi 2.2. [2] Polinomial Chebyshev jenis kedua $U_{N}(x)$ berderajat $N$ didefinisikan sebagai

$$
U_{N}(x)=\frac{\sin (N+1) \theta}{\sin \theta} \text { dengan } x=\cos \theta .
$$

\section{Titik Nol dan Titik Chebyshev}

Titik nol merupakan titik $x=\cos \theta$ dimana $\theta$ diperoleh dari polinomial Chebyshev $T_{N}(x)$ dan $U_{N}(x)$ yang bernilai nol. Karena $x=\cos \theta \in[-1,1]$, maka $\theta \in[0, \pi]$. Untuk polinomial Chebyshev jenis pertama $T_{N}(x)=\cos N \theta=0$ dipenuhi ketika

$$
N \theta=\left(j-\frac{1}{2}\right) \pi, \quad j=1,2, \cdots, N .
$$

Dengan demikian titik nol dari $T_{N}(x)$ adalah

$$
x=x_{j}=\cos \left(\frac{\left(j-\frac{1}{2}\right) \pi}{N}\right), \quad j=1,2, \cdots, N .
$$

Selanjutnya untuk polinomial Chebyshev jenis kedua $U_{N}(x)=0$ dipenuhi ketika

$$
\sin (N+1) \theta=0
$$


sehingga diperoleh

$$
(N+1) \theta=j \pi, \quad j=1,2, \cdots, N .
$$

Dengan demikian titik nol dari $U_{N}(x)$ adalah

$$
x=x_{j}=\cos \frac{j \pi}{(N+1)}, \quad j=1,2, \cdots, N .
$$

Dengan menambahkan $y_{0}=1$ dan $y_{N+1}=-1$, persamaan (2.4) menjadi

$$
x=x_{j}=\cos \frac{j \pi}{(N+1)}, \quad j=0,1, \cdots, N+1 .
$$

Akibatnya, persamaan (2.5) bukan merupakan titik nol dari $U_{N}(x)$, tetapi merupakan titik nol dari polinomial

$$
\left(1-x^{2}\right) U_{N}(x)
$$

Titik Chebyshev dari $T_{N}(x)$ merupakan titik nol pada turunan pertama dari $T_{N}(x)$ yang diberikan oleh

$$
\frac{d}{d x} T_{N}(x)=\frac{-N \sin N \theta}{-\sin \theta}=0 .
$$

Akibatnya,

$$
\begin{aligned}
\sin N \theta & =0 \\
N \theta & =j \pi, \quad j=1,2, \cdots, N .
\end{aligned}
$$

Selanjutnya dengan menambahkan $x= \pm 1$, titik Chebyshev dari $T_{N}(x)$ pada $[-1,1]$ adalah

$$
x=x_{j}=\cos \frac{j \pi}{N}, \quad(j=0,1, \cdots, N)
$$

\section{Metode Pseudospektral Chebyshev}

Diberikan sebuah fungsi $v(x)$ yang terdefinisi dan terdiferensialkan pada $[-1,1]$. Diperoleh turunan $v^{\prime}(x)$ berdasarkan langkah-langkah berikut:

(1) Diskritisasi interval $[-1,1]$ menggunakan titik Chebyshev (2.7), yaitu

$$
x_{j}=\cos \left(\frac{j \pi}{N}\right), \quad j=0,1, \cdots, N .
$$

Nilai fungsi $v(x)$ di setiap titik $x_{j}$ ditulis sebagai $v_{j}=v\left(x_{j}\right)$ untuk $j=$ $0,1, \cdots, N$. Selanjutnya definisikan vektor $\boldsymbol{v}=\left[v_{0}, v_{1}, v_{2}, \cdots, v_{N}\right]^{T}$.

(2) Tentukan polinomial interpolasi $p(x)$ berderajat paling tinggi $N$ sedemikian sehingga

$$
p\left(x_{j}\right)=v_{j}, \quad j=0,1, \cdots, N .
$$

(3) Dapatkan vektor turunan $\boldsymbol{v}^{\prime}$ dengan menurunkan $p(x)$ dan mengevaluasinya di setiap titik $x_{j}$, yaitu

$$
v_{j}^{\prime}=p^{\prime}\left(x_{j}\right), \quad j=0,1, \cdots, N .
$$


Prosedur ini mendefinisikan matriks diferensiasi berukuran $(N+1) \times(N+1)$, dinotasikan sebagai $D_{N}$, yang diberikan oleh

$$
\boldsymbol{v}^{\prime}=D_{N} \boldsymbol{v}
$$

dimana $\mathbf{v}^{\prime}=\left[p^{\prime}\left(x_{0}\right), \cdots, p^{\prime}\left(x_{N}\right)\right]^{T} \operatorname{dan} \mathbf{v}=\left[p\left(x_{0}\right), \cdots, p\left(x_{N}\right)\right]^{T}$.

\section{Matriks Diferensiasi}

Matriks diferensiasi $D_{N}$ diberikan oleh

$$
D_{N}=\left(\begin{array}{ccccc}
\left(D_{N}\right)_{00} & \left(D_{N}\right)_{01} & \left(D_{N}\right)_{02} & \cdots & \left(D_{N}\right)_{0 N} \\
\left(D_{N}\right)_{10} & \left(D_{N}\right)_{11} & \left(D_{N}\right)_{12} & \cdots & \left(D_{N}\right)_{1 N} \\
\left(D_{N}\right)_{20} & \left(D_{N}\right)_{21} & \left(D_{N}\right)_{22} & \cdots & \left(D_{N}\right)_{2 N} \\
\vdots & \vdots & \vdots & \ddots & \vdots \\
\left(D_{N}\right)_{N 0} & \left(D_{N}\right)_{N 1} & \left(D_{N}\right)_{N 2} & \cdots & \left(D_{N}\right)_{N N}
\end{array}\right) .
$$

Pandang koefisien polinomial interpolasi Lagrange yang diberikan oleh

$$
L_{j}(x)=\frac{\prod_{k=0, k \neq j}^{N}\left(x-x_{k}\right)}{\prod_{k=0, k \neq j}^{N}\left(x_{j}-x_{k}\right)}, \quad j=0,1, \cdots, N .
$$

Misalkan

$$
p_{j}(x)=\frac{P_{N}(x)}{x-x_{j}},
$$

dimana

$$
P_{N}(x)=\prod_{k=0}^{N}\left(x-x_{k}\right)
$$

maka

$$
\begin{aligned}
p_{j}\left(x_{j}\right)=P_{N}^{\prime}\left(x_{j}\right), & p_{j}\left(x_{i}\right)=0 \\
p_{j}^{\prime}\left(x_{j}\right)=\frac{1}{2} P_{N}^{\prime \prime}\left(x_{j}\right), & p_{j}^{\prime}\left(x_{i}\right)=\frac{P_{N}^{\prime}\left(x_{i}\right)}{x_{i}-x_{j}} .
\end{aligned}
$$

Dengan menjadikan $p(x)=p_{j}(x)$ pada persamaan (3.1), didapatkan entri-entri matriks $D_{N}$ sebagai berikut.

$$
\begin{aligned}
\left(D_{N}\right)_{j j} & =\frac{1}{2} \frac{P_{N}^{\prime \prime}\left(x_{j}\right)}{P_{N}^{\prime}\left(x_{j}\right)} . \\
\left(D_{N}\right)_{i j} & =\frac{P_{N}^{\prime}\left(x_{i}\right)}{\left(x_{i}-x_{j}\right) P_{N}^{\prime}\left(x_{j}\right)} .
\end{aligned}
$$

Secara umum, entri-entri matriks diferensiasi Chebyshev diberikan oleh teorema berikut. 
Teorema 3.1. [5] Untuk setiap $N \geq 1$, misalkan baris dan kolom matriks diferensiasi Chebyshev $D_{N}$ yang berukuran $(N+1) \times(N+1)$ diberi indeks dari 0 sampai N. Entri-entri dari matriks tersebut adalah

$$
\begin{gathered}
\left(D_{N}\right)_{00}=\frac{2 N^{2}+1}{6}, \\
\left(D_{N}\right)_{N N}=-\frac{2 N^{2}+1}{6}, \\
\left(D_{N}\right)_{j j}=\frac{-x_{j}}{2\left(1-x_{j}^{2}\right)}, \quad j=1,2, \cdots, N-1, \\
\left(D_{N}\right)_{i j}=\frac{c_{i}}{c_{j}} \frac{(-1)^{i+j}}{x_{i}-x_{j}}, i \neq j, \quad i, j=0,1, \cdots, N,
\end{gathered}
$$

dimana

$$
c_{i}= \begin{cases}2, & \text { untuk } i=0 \text { atau } i=N \\ 1, & \text { untuk yang lainnya. }\end{cases}
$$

Bukti. Misalkan $N+1$ titik partisi diberikan oleh $x_{j}=\cos \frac{j \pi}{N}$ yang merupakan titik Chebyshev pada selang $[-1,1]$. Karena $x_{j}$ juga merupakan titik nol dari polinomial $\left(1-x^{2}\right) U_{N-1}(x)$, maka $P_{N}(x)=\left(1-x^{2}\right) U_{N-1}(x)$. Substitusi $x=\cos \theta$ memberikan

$$
\begin{aligned}
P_{N}(x) & =\left(1-\cos ^{2} \theta\right) \frac{\sin N \theta}{\sin \theta} \\
& =\sin \theta \sin N \theta .
\end{aligned}
$$

Turunkan $P_{N}(x)$ terhadap $x$ dengan mengggunakan aturan rantai, diperoleh

$$
P_{N}^{\prime}(x)=-\left(\frac{\cos \theta \sin N \theta+N \sin \theta \cos N \theta}{\sin \theta}\right)
$$

dan

$$
P_{N}^{\prime \prime}(x)=-\left(\frac{\cos ^{2} \theta \sin N \theta-N \sin \theta \cos \theta \cos N \theta+\left(1+N^{2}\right) \sin ^{2} \theta \sin N \theta}{\sin ^{3} \theta}\right)
$$

Karena $\theta_{j}=\frac{j \pi}{N}$ maka $\sin N \theta_{j}=0$ dan $\cos N \theta_{j}=(-1)^{j}$. Karena $x_{j}=\cos \theta_{j}$, maka persamaan (3.4) menjadi

$$
P_{N}^{\prime}\left(x_{j}\right)= \begin{cases}-(-1)^{j} N, & 0<j<N, \\ -2 N, & j=0, \\ -2(-1)^{N} N, & j=N,\end{cases}
$$

dan persamaan (3.5) menjadi

$$
P_{N}^{\prime \prime}\left(x_{j}\right)= \begin{cases}(-1)^{j} N \frac{x_{j}}{1-x_{k}^{2}}, & 0<j<N, \\ -2 N \frac{1+2 N^{2}}{3}, & j=0, \\ 2(-1)^{N} N \frac{1+2 N^{2}}{3}, & j=N .\end{cases}
$$


Substitusi persamaan (3.6) dan persamaan (3.7) ke persamaan (3.2) dan persamaan (3.3) menghasilkan formula entri-entri dari matriks $D_{N}$ sebagai berikut:

$$
\begin{gathered}
\left(D_{N}\right)_{00}=\frac{2 N^{2}+1}{6}, \\
\left(D_{N}\right)_{N N}=-\frac{2 N^{2}+1}{N}, \\
\left(D_{N}\right)_{j j}=\frac{-x_{j}}{2\left(1-x_{j}^{2}\right)}, \quad j=1,2, \cdots, N-1, \\
\left(D_{N}\right)_{i j}=\frac{c_{i}}{c_{j}} \frac{(-1)^{i+j}}{x_{i}-x_{j}}, \quad i \neq j, \quad 1, j=0,1, \cdots, N,
\end{gathered}
$$

dimana

$$
c_{i}= \begin{cases}2, & \text { untuk } i=0 \text { atau } i=N . \\ 1, & \text { untuk yang lainnya. }\end{cases}
$$

\section{Implementasi Numerik}

Sebagai contoh ilustrasi, fungsi yang akan dihitung turunannya adalah

$$
v(x)=\exp (x) \sin (5 x) \text { untuk } x \in[-1,1] .
$$

Berikut algoritma dalam menghitung aproksimasi turunan fungsi dengan menggunakan metode pseudospektral Chebyshev.

Masukan:

$v(x)$ (fungsi yang akan diturunkan).

$N$ (banyak titik partisi).

$d v$ (fungsi turunan eksak).

\section{Keluaran:}

$h d v$ (hampiran turunan fungsi).

eror (galat).

Langkah-langkah:

(1) $x[j]:=\cos (j \pi) / N$ untuk $j=0,1, \cdots, N$ (titik-titik partisi).

(2) $v[j]:=v(x[j])$ untuk $j=0,1, \cdots, N$ (nilai-nilai fungsi $v$ di $x[j]$ ).

(3) $d v[j]:=d v(x[j])$ untuk $j=0,1, \cdots, N$ (nilai-nilai fungsi turunan $d v$ di $x[j]$ ).

(4) Konstruksi matriks diferensiasi Chebyshev

Konstruksi matriks diferensiasi Chebyshev berpedoman pada Teorema 3.1 dan merujuk pada referensi [5].

(5) $h d v:=D * v$.

(6) eror $:=\operatorname{norm}(h d v-d v)$. 
Algoritma tersebut kemudian diimplementasikan pada aplikasi pemrograman MATLAB. Berikut plot hasil metode pseudospektral Chebyshev dan metode beda hingga pada fungsi $v(x)$ serta perbandingan galatnya.

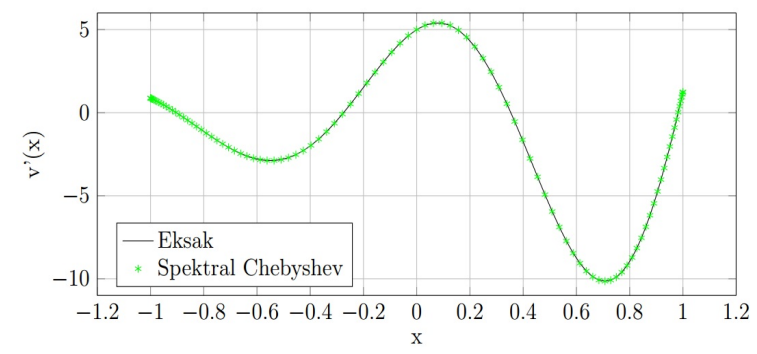

Gambar 1. Nilai Eksak dan Nilai Hampiran Pseudospektral Chebyshev Fungsi v'(x).

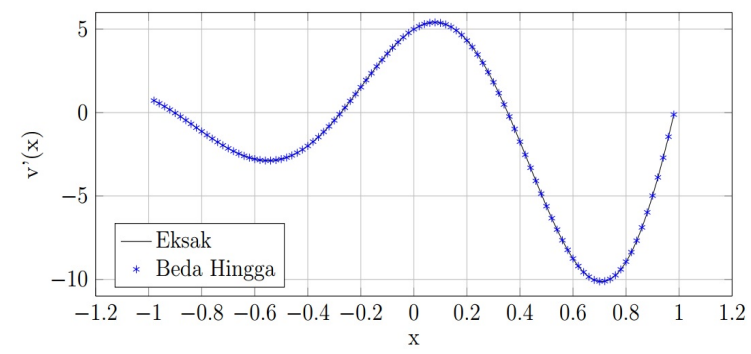

Gambar 2. Nilai Eksak dan Nilai Hampiran Beda Hingga Fungsi v'(x).

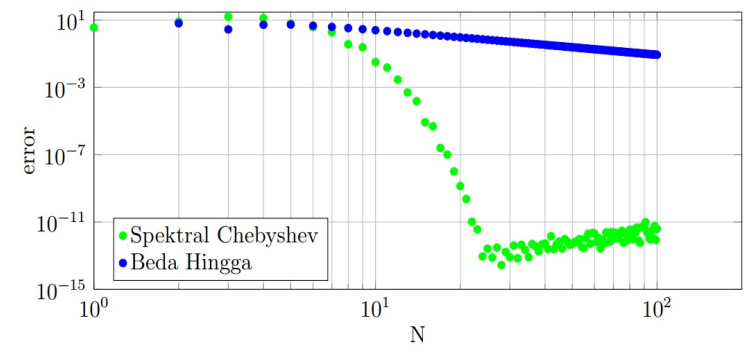

Gambar 3. Perbandingan Galat Metode Pseudospektral Chebyshev dan Beda Hingga.

Berdasarkan Gambar 1 dan Gambar 2 dapat dilihat bahwa metode pseudospektral Chebyshev dapat mengaproksimasi turunan fungsi dengan dengan sangat baik. Dari perbandingan galat metode beda hingga dan metode pseudospektral Chebyshev pada Gambar 3 dapat disimpulkan bahwa metode pseudospektral jauh lebih baik dalam mengaproksimasi turunan fungsi dibandingkan dengan metode beda 
hingga. Hal tersebut dapat dilihat dari galat metode pseudospektral Chebyshev yang jauh lebih kecil dibandingkan metode beda hingga.

\section{Kesimpulan}

Dari hasil implementasi numerik yang membandingkan aproksimasi turunan fungsi dari metode pseudospektral Chebyshev dengan metode beda hingga, dapat disimpulkan bahwa metode pseudospektral Chebyshev menghampiri nilai turunan eksak dari suatu fungsi dengan sangat baik. Metode pseudospektral Chebyshev dapat mengaproksimasi fungsi secara umum dengan tingkat keakuratan yang sangat tinggi.

Untuk penulisan selanjutnya, penulis menyarankan hal-hal berikut

(1) Penjelasan mengenai konstruksi metode pseudospektral dapat dikembangkan untuk menyelesaikan permasalahan mengenai persamaan diferensial.

(2) Untuk mengetahui keakuratan metode pseudospektral Chebyshev, perlu dilakukan analisis galat.

\section{Ucapan Terima kasih}

Penulis mengucapkan terima kasih kepada Bapak Mahdhivan Syafwan, Bapak Admi Nazra, Bapak Yudiantri Asdi, Bapak Syafrizal Sy, dan Ibu Lyra Yulianti yang telah memberikan masukan dan saran sehingga makalah ini dapat diselesaikan dengan baik.

\section{Daftar Pustaka}

[1] Mathews, John H., K.D. Fink. 1992. Numerical Methods for Computer Science, Engineering, and Mathematics. Edisi ke-2. Prentice-Hall, Englewood Cliffs.

[2] Mason, J.C., D.C. Handscomb. 2003. Chebyshev Polynomials. CRC Press. New York.

[3] Pebrizal, M.F. 2015. Penggunaan Metode Pseudospektral pada Aproksimasi Turunan Fungsi Periodik. Universitas Andalas. Padang.

[4] Trefethen, Llyod N. 1996. Finite Difference and Spectral Methods for Ordinary and Partial Differential Equation. Upson Hall, Ithaca.

[5] Trefethen, Llyod N. 2000. Spectral Methods in Matlab. SIAM: Society for Industrial and Applied Mathematics. Philadelphia. 